Dialectologia 19 (2017), 93-107.

ISSN: 2013-2247

Received 28 July 2015.

Accepted 12 October 2015.

\title{
TRANSLATING DIALECT EMBEDDED IN NAJDI PROVERBS INTO ENGLISH
}

Sayed M. ISMAIL

\author{
Sattam bin Abdualziz University* \\ sayedism@gmail.com
}

\begin{abstract}
The study attempts to provide an insight into the problematic issues arising from translating dialect embedded in common sayings and proverbs. It proposes solutions to the problems of translating dialects. Owing to the fact that dialect has a cultural singularity and social privacy, it is only understood by the people who use it in their daily life. Thus, when an Arab translator attempts to translate dialect, he will be faced by a wide spectrum of problematic issues. For example, he/she cannot understand the meaning of the dialectal words in the same source language. In addition, he will not be knowledgeable about the cultural, social, and historical factors that change the meaning of these words. In addition, dialect is a form of oral speech which is delivered from a generation to generation through daily life contact. Accordingly, many words are subject to rapid changes and other words can be corrupted and distorted. These issues represent a great challenge for translators working in such a field. Thus, the study attempts to provide a translation approach which may constitute a good starting point for dealing with such problems.
\end{abstract}

\section{Keywords}

dialect, polysystem theory, intralingual translation, cultural understanding

\section{TRADUCCIÓN AL INGLÉS DE DIALECTALISMOS DE LOS PROVERBIOS EN NAJDI}

\section{Resumen}

El estudio intenta penetrar en los temas problemáticos que surgen al traducir dialectalismos incluidos en refranes y proverbios habituales. Propone soluciones a los problemas de traducción de

* Prince Sattam Bin Abdulaziz University, Alkharj Community College. Abu Dajan Street- Al-montzha District. P.O. BOX: 1866, Alkharj 11942, Riyadh, Kingdom of Saudi Arabia. 
dialectos. Puesto que el dialecto tiene una singularidad cultural y privacidad social, es sólo entendido por los hablantes que lo usan en su vida cotidiana. Así, cuando un traductor árabe intenta traducir el dialecto, se enfrenta a un amplio espectro de cuestiones problemáticas. Por ejemplo, no puede entender el significado de las palabras dialectales en el idioma de origen y no está bien informado sobre los factores culturales, sociales e históricos que cambian los significados de estas palabras. Además, el dialecto es una forma de discurso oral que pasa de una generación a otra a través del contacto de la vida diaria. En consecuencia, muchas palabras están sujetas a cambios rápidos y otras palabras pueden ser corrompidas y distorsionadas. Estas cuestiones representan un gran desafío para los traductores que trabajan en este campo. Por lo tanto, el estudio intenta proporcionar un enfoque de traducción que puede constituir un buen punto de partida para abordar estos problemas.

\section{Palabras clave}

dialecto, teoría del polisistema, traducción intralingual, comprensión cultural

\section{Introduction}

Translating dialect is a controversial issue as dialect is distinct from both classical Arabic and Modern Standard Arabic. Dialect is known for its narrow locality. In other words, dialect is spoken by a small group of people or members of the same community who share in common certain linguistic, ethnic, and cultural features. Thus dialect is mainly associated with slangs, vernacular speech, daily conversations, and informal speech and so on. Traditional forms of literature and folklore attempt to keep dialects and vernacular speech surviving and vice versa. Thus, the Saudi culture draws unrivalled attention to the issue of dialect protection because it represents a major channel that not only protects the inherited tradition from loss or oblivion but also keeps it alive for the next generations. Accordingly, Saudi modern and pre-modern literature abounds in dialects and vernacular speech.

The varieties of dialects in Saudi are influenced by various factors such as its tribal filiations, geographical or regional affiliations, socioeconomic conditions, the modern urbanization, the spread of education and the mass media in most parts of the Kingdom, and the waves of immigrations from neighboring Arab and the Asian countries for work. 


\section{The significance of research}

Saudi is divided into two main regions, Hejaz region and Najd region. Each main region includes subsidiaries regions with a variety of dialects, slangs, traditions and tribes. The locality and the linguistic specificity of each dialect may sometimes cause miscommunication and misunderstanding not only between Saudi people and non-Saudi Arab but also among the Saudi people themselves. Thus, the idea of rendering such dialect into English may cause a major problem of understanding for the Arab translators, whether they are Saudi or non-Saudi. In addition, the development of dialects is associated with various social, religious-geographical and cultural factors.

\section{Research problems}

The research deals with various problems related to translating dialects. Firstly, dialect is different from classical Arabic and modern standard Arabic (MSA). These differences can be phonological, lexical, grammatical, etymological and cultural. Accordingly, when an Arab translator attempts to translate dialect into English, which is not in MSA or different from his special dialect, he will be faced by a problem of lack of understanding to variety of dialectal terms and expressions used in the source text. Thus, the translation problematic in such a case is twofold; the first is related to understanding within the same source language and the second is associated with rendering the source language into English. Secondly, another problem which faces the translator of dialect into English is that how he/she could preserve and keep such dialect notion of the source language unchanged in the target langue. In other words, how can he/she render the dialect to another dialect, not formal language? Finally, because dialects represent vernacular speech and slangs, different from the modern Standard Arabic and Classical Arabic, they are vulnerable to various changes that range from semantic, lexical, and etymological and so on, which may bring about difficulties in translation. 


\section{Methodology}

The research will use both the analytical and comparative methodology. The analytical methodology will be used to analyze linguistically some examples taken from the forms of literature and proverbs of Najd region that demonstrate to what extent the dialect can affect the process of translation/interpretation into English. The linguistic analysis of Najd dialect being presented in these literary forms will be coupled with a cultural analysis. It will compare these examples to both Modern Standard Arabic and their equivalence in English culture.

\section{Review of literature}

The studies written in English dealing with translating the Saudi dialects into English are a few in number. In most cases, these studies focused on the equivalence theories of translation. The dialectical expressions cannot be rendered simply through word for word or equivalence theories of translation because they are overloaded with long-standing historical tradition that fused with the present actualities.

In his unpublished PhD dissertation entitled, A Critical and Comparative Study of Modern Najd Arabic Proverbs, Muhammad Al-Suliman Al-Saudis (1950) did a marvelous effort in collecting a great deal of modern and classical Saudi proverbs widely used in Najd area and endeavored hard to translate them into English. Pursuing the translation of proverbs, he totally circumvented any reference to the dialect embedded in the body of these proverbs. Rather, he confined the translation process of the proverbs to the linguistic theories of translation. In addition, he failed to present the cultural connotations implicit in the original message intended by the author or the proverb narrator.

In his article, "The Golden Middle in Translating form Arabic, e.g. into English", Bahaa M. Mezid (2008) argues for presenting solutions for translating the texts written in classical Arabic language or in any of the colloquial varieties of the Arabic language. He proposed that the intranligual approach be used as a better method to translate the 
texts embedded with dialects. However, he did not explain how the translator can use the intralingual approach for rendering classical words whose connotations have been changing overtime.

\section{Classical Arabic, modern standard Arabic (MSA) and Najd dialect}

C. A. Ferguson explains that Arabic speaking language is characterized by diglossia, which is defined as "two or more varieties of the same language are used by some speakers under different conditions" (1959: 325). He divides Arabic into the following varieties: Classical Arabic, Modern Standard Arabic and Vernacular speech. Modern Standard Arabic (MSA) is used in sermons and other formal contexts. Vernacular speech or slang is spoken in everyday conversations and other informal encounters. According to Thompson \& Werfelli (2012), modern standard Arabic (MSA) is defined as follows:

\footnotetext{
This is the language used in the Arabic-speaking world for most written texts - it is the language of newspapers, of the media, and of the school system. In addition to this form of Arabic, also well-studied in the Islamic intellectual tradition is Classical Arabic, which is the form of Arabic found in the Qur'an, the Muslim holy book (Thompson \& Werfelli 2012: 2)
}

MSA is different from dialect at different levels. These differences can be represented in vocabulary, syntax, morphology, and spelling. For example, dialects use their own lexical choices for articulating their concepts. The concept corresponding to Oryd ('I want') is spoken as Awz in Egyptian, Abgy in Gulf, bdy in Lebanon and Syria. Some examples of words and expressions that vary from one colloquial variety of Arabic to other are as follows: (1) 'very much': barshabarsha (Tunisian), waajid and waayid (Gulf, UAE, Kuwait), ђeel, marrah (Gulf, Saudi), biz-zaaf (Moroccan), qawi and ?awi, jiddan and giddan (Egypt); (2) 'man, guy': raajil and raagil, gadaa (Egypt), zalamih (Levant, Syrian, Lebanese), zoul (Sudanese); (3) 'now': dilwa?ti, dilwakiit, dilawakiiti, and dilwak (Egypt), al Ђiin and da நiin (Saudi), hassih (Iraqi, Jordanian); (4) 'thus, as such': 
kida,; kdih and kidahawwiiti (Egypt), heek (Syrian, Lebanese), tshi (UAE), hakka (Tunisian).

In addition to the lexical differences between MSA and dialect, there are also phonological differences. For example, these differences can be reflected through the glottal stop. The word /ra?s/ (head) as opposed to the vernacular /ra:s/ (Versteegh 1997: 99). In addition, the uvular /q/ is used in Standard Arabic, in Saudi dialects it is replaced by [g], [k], and [?]. For example [hagi:ga] is the /haqi:qa/ (truth). On the other hand, in some Egyptian and Syrian dialects /q/ is pronounced as glottal [?], thus /ḥaqi:qa/ is realized as [ḥa?i:?a].

Dialect is defined as "a language variety which is used in geographically limited part of a language area in which it is roofed by a structurally related standard" (Hinskens \& Auer 2005: 1). The environment of the dialect is a part of larger environment that encompasses various dialects. Such comprehensive environment is called language. Classists sometimes defines it as a language. They also define it as distortion of speech (Anis 1965: 15). Each dialect has its distinct linguistic features and cultural singularity that makes it different from other dialects. "A dialect typically displays structural peculiarities in several language components" (Chambers \& Trudgill 1998: 5). Each dialect has its own separate phonological features which are different from the other dialects. For example, Bani Assad tribe pronounced Sakra 'drunk' as Skra'na. In addition, a part of Tamim tribe, used the word Madayoun, indebted, instead of made. Differences are not only limited to phonological differences but also lexical. Some Arabic dictionaries explained that Hejazi people defines word Hagrs as 'monkey' and Tammi tribe defines it as 'fox' (Anis 1965: 16).

\section{Translating Najd dialect in proverbs}

The process of translating the proverbs and the literary works embedded with Najd dialects would generate various problematic issues. First of all, the meaning of the dialectal words is largely influenced by the surrounding culture. The translator may find a further difficulty if he/she tries to understand or to get the meaning of the dialectal 
words without linking them with their broader context. The dialect words cannot be separated from the things that produce them to the outside reality. Peter Behnstedt (2009) puts it clearly in the following lines:

It simply means that one has not only to study " the words", their meanings and history, but also the "things", the cultural artefacts and concepts, which are designated. The concept is meanwhile well-established, and to come right to the point: "a lamb within an Arab sheep -rears' world is not simply a lamb", it might be "weaned", "fat", "have two or four new incisors", it might be" one year old or two" and consequently have different names. "A well" in Arabic dialects is not simply a well, it may be deep, shallow, narrow, broad, dry in summer, have much water, have little water, it may be walled or not, with bricks or something else, etc. Accordingly, different designations may be used (Behnstedt 2009: 63)

Translating a dialectal word into English is not a simple issue as in many cases "the lexicological issues reflect the interpretation of a given culture" (Cappuccio 2005: 47). Thus, dialects need a deep understanding of the cultural elements embedded in them that have changed their meaning across time and space. In other words, a dialectal word in itself receives its meaning from its cultural context. For example, according to Najd dialect the slang word mokhanfas means 'easily provoked' or 'angry man' (Algebali 1990: 130). However, according to the Egyptian dialect, mokhanfas means 'long-curly haired man'. In Najd dialect, the Arabic word akal means 'to spoil', 'to damage or to corrupt something'. This is explained in the following saying, albard akel alrebei, which can be rendered into English as follows: 'cold damages the seeds of the wheat'. In the modern standard Arabic language, akel means 'to eat something' (Alqweai 1994: 80). In the Arabic dictionaries, the Arabic word alrebei means 'blossoming' and also means 'the son of a young man'. Thus, the historical element and external cultural influences changed the meaning of the word alrebei, which means 'the son of a young man', into 'the seeds of the wheat'. This may draw our attention toward an important conclusion that the words used in dialects acquired new connotations to be different from the formal and modern standard Arabic language. Dialect is deeply associated with its 
cultural environment.

Another example which may explain how the dialectal word could receive a totally distinct meaning from its surrounding culture is the word jard. This word means 'cavalry'. People in Naijd uses it in the following context: ghaza fellan bee sard and jard (Hamed 1990: 33). It can be rendered into English as follows: 'Mr. X, invades by shields and cavalry'. However, in formal Arabic dictionaries, the word jard has almost different meanings and distinct connotations such as a 'inventory', 'waste land', and so on. Accordingly, the dialectal words or vernacular speech share the same orthographic letters with the formal Arabic language but the differences can be shown clearly in the pronunciation, meaning, and cultural connotations.

Being informed of the lexical, semantic and phonological differences between the formal Arabic language and the dialect of Najd, one can admit that the translation theories based on the word for word would fail to provide an accurate and precise translation. Thus, the question being addressed in this context as follow: how could we translate such terms? Which translation methodology is recommended to render Najd dialectal terms embedded in proverbs and literary genres such as poetry, drama and so on? Taking into consideration the idea that dialect is largely used in oral speech rather than the written texts.

\section{Translation theories and translating dialect}

Obviously, the issue of dialect translation is such a complicated and intricate due to the aforementioned reasons. Indeed, the previous studies recommended to use the intralingual approach for better understanding in the same source language (Mezid 2008, Dickins 1990). Roman Jakobson in his article "On Linguistic Aspects of Translation" (1959) explains that message being communicated through translation is always incomplete, as the linguistic equivalence never totally communicates the full message of the original text. However, there is always something missing and incomplete in the translated text. He uses the word 'cheese' in English as an example. This word is not identical to the Russian word or code-unit "syr" since the latter does not include the 
concept of cottage cheese (Venuti 2000: 114). When the linguistic terminology fails to provide an accurate and precise translation, according to Jakobson, the translator should resort to using loanwords or loan-translations, neologisms or semantic shifts (Venuti 2000: 115). Thus, Jakobson's substitution policy on the level of the word is not sufficient for providing a good translation because the translator is still turning around the vicious circle of the word substitution policy. However, the major influence does not rest upon the linguistic rendering of the dialectal word but in the cultural influence that changes the meaning of the word across time to be a newly born word that is different from both Modern Standard Arabic and classical Arabic.

In his book, Toward a Science of Translating (1964), Eugene Nida argues for dynamic equivalence that can fill in the cultural gap between two different languages. The dynamic equivalence follows the cultural standard of the target text; it is away to adapt the source text to the culture of the target text. The translation process, however, is limited to rendering word for word. According to Munday (2001: 38), Nida focused the translation process on the context of the target text.

In Comparative Stylistics of French and English: A Methodology for Translation (1995), Jean-Paul Vinay and Jean Darbelent provide two translation strategies for handling the problematic issues arising from translating culturally embedded texts. These two translation strategies are direct and oblique strategies. They confined the problematic issues arising from translating culturally embedded texts to "structuralism parallelism" and the "metalinguistic parallelism". Thus, the direct and oblique strategies deal with the syntactic, lexical and stylistic issues. However, there is a remarkable parallelism ignored by such a theory: cultural parallelism. The linguistic theories of translation such as Catford's (1965) formal correspondence and textual equivalence, Katharina Reiss's (1971) theory of text type model, Vermeer's (1989) Skopos theory partly fails to deal with the problematic issues arising from translating texts embedded with dialectal terms and vernacular speech.

Accordingly, the convenient approach for rendering the dialectal terms embedded in Najd proverbs and literature is such an approach that considers translation a bridging vehicle between cultures. In other words, translated works should imitate the original literary work; it has to mimic the forms of literary text in the target language. Thus, 
translated text has to be culturally and linguistically manipulated in order to be relevant to the target cultural system and its aesthetic and poetic forms. In this way, translation has to be employed as an act of representation. Itamar Even-Zohar clearly puts it as follows:

The idea that semiotic phenomena, i.e., sign-governed human pat- terns of communication (such as culture, language, literature, society), could more adequately be understood and studied if regarded as systems rather than conglomerates of disparate elements has become one of the leading ideas of our time in most sciences of man. Thus, the positivistic collection of data, taken bona fide on empiricist grounds and analyzed on the basis of their material substance, has been replaced by a functional approach based on the analysis of relations. Viewing them as systems made it possible to hypothesize how the various semiotic aggregates operate (Even-Zohar 1990: 10).

According to Even-Zohar, the translation process of a given text has to fully focus on the whole system affecting the text and producing it to the reality. The cultural, linguist, historical and social elements should be taken into consideration while translating a literary text into English. Furthermore, "being placed in this way in a larger sociocultural context, 'literature' comes to be viewed not just a collection of texts, but more broadly as a set of factors governing the production, promotion and reception of these texts" (Baker \& Malmkjaer 1998/2001: 176-177). Thus, adopting Even-Zohar theory of translation can be helpful in handling the problematic issues arising from translating the vernacular speech and slang language". "Translation is no longer a phenomenon whose nature and borders are given once and for all, but an activity dependent on the relation within a certain cultural system" (Even-Zohar 1990: 51).

Accordingly, the researcher proposes the following steps for translating dialect embedded in Najdi proverbs. Firstly, applying the intralingual concept of translation in order to understand, explain and interpret the vernacular speech and dialect words whose meaning and cultural connotations are ambiguous and clumsy in Arabic. Secondly, the translator has to study the role of the cultural impact on the texts being translated. This cultural influence should trace the historical and social changes and 
their association with the development and change of meaning of dialectal terms. Thirdly, it questions whether dialectal words are fixed in meaning or changed over time. Fourthly, it tries to adapt and appropriate the translated text to fit the poetic and literary forms of the target culture. Finally, the process of translation is not only confined to search for linguistic equivalence; rather, the translator has to render his/her text against the grains of the entire tradition and culture. In other words, translation process should start from the smaller units to the larger units and the vice versa. That is to say, what is not clearly stated by focusing on the smaller units can be revealed by examining the larger units.

\section{Samples and analysis}

First, the researcher not only attempts to translate the Najdi proverb but also explains the process of their translation, focusing on the problematic issues arising from encountering this translation. Translating the proverb, la teferha be soraat omak ala altanour, the translator does not face any problem on a linguistic level. The language is simple and the words can be easily rendered into English. The question posed is this: can linguistic equivalence provide us with the intended meaning of the proverb? A purely linguistic approach translates this proverb as 'Do not feel happy about your mother's quick performance at the oven'. This translation appears meaningless and does not communicate any kind of message to a Western reader. It has nothing to do with the core value of the proverb, which is intended to communicate a clear and intelligible message to the addressed party.

A cultural interpretation of the Arabic proverb is needed. In other words, the proverb has to be understood and interpreted within its broader context. The historical and socio-economic realities associated with the text have to be investigated prior to translating it. In this proverb, the speaker is warning the listener about the risks of being overly optimistic or from holding unrealistic expectations. The historical context, in which such proverb was produced, is a perquisite for providing true and precise translation. In this context, the addressee may feel pleased at the expectation that 
his/her mother is preparing a delicious meal for a few moments time. However, summoning up the historical context in which such a proverb was said can help us provide a true translation and this can communicate the core message of the original text without misrepresenting it. The historical context in which this proverb was said relates to scarcity of food and the lack of essential ingredients for cooking a good and delicious meal. As such it speaks of the mother cooking a meal very quickly because of a lack of resources" (Abdelmehssn 1997: 6).

Simple linguistic equivalence is irrelevant, unnecessary and does not communicate the invisible and concealed message of the proverb. Therefore, it is necessary to translate the invisible message of the proverb or the authorial or the speaker's intention. The speaker's intention or the authorial intention may be common among the members of Najd community, as it is a wise old saying with a clear association and a recognized situation. The English receiver lacks these cultural elements that would help reveal the ambiguity in meaning and clarify it. The task of the translator is neither simple nor easy because he/she has to transfer the paralinguistic elements of the source text to the target text. Subsequently, the unseen elements, invisible cultural notion, should be translated into seen elements and visible cultural notion in order to deliver a precise and clear meaning to the receiver. The wisdom of this saying is that one should not raise one's expectations to high and unachievable levels as this will lead to disappointment. The translator has to presuppose the historical background of the text, which can be achieved through understanding the contextual situation out of which the proverb was born and used.

Furthermore, the translation process needs to be culturally and linguistically adapted to the target culture. The translator has to search for an English equivalent which conveys the same concept as the Arabic. One possible translation of the abovementioned proverb could be 'blessed is he who expects nothing, for he shall never be disappointed' (Oxford Dictionary of Proverbs). Translating the following proverb, Emdhani waa Khod Abyati, the translator has to avoid using the linguistic equivalent or literal translation, 'praise me and take my cloak'. This proverb is similar to the Egyptian saying, laqeeni wa la taghdeeni. In most idiomatic translation, this proverb is translated as follows: 'I'd rather be well received than well fed' (Better warm welcome than being 
invited to lunch). This translation is far beyond the authorial intention or the true meaning of the saying. In the Arab culture, this saying urges the addressee to welcome his guest warmly. The proposed method for translating this proverb is to search for the English proverb which communicates a similar message. Thus, it can be translated as follows: 'First impressions are the most lasting' (Oxford Dictionary for Proverbs).

'He is as tall as palm tree but his mind is as foolish as the kid' is literal translation of the following proverb, altwool tool nakhlawaa akalakl sakhla. This translation is void of poetic and atheistic language and does not agree well with the cultural values of the receiver, as 'the kid' is not the same symbol of foolishness in English culture. It does not convey a clear or understandable message for the reader, as it does not render the true meaning of the proverb. A proposed equivalent in English could be 'a little body does often harbor a great soul' or 'little things please little minds' (Oxford Dictionary of Proverbs).

\section{Conclusions}

The research reached a conclusion that the Dialect of Najd is translatable. However, the process of translating dialect requires an understanding of the nature of dialect as an oral speech, which is changeable, and renewable. A major problem facing the translators, who are concerned with rendering dialect, is their inability to understand the dictions and the words used in dialects. In addition, translating dialect cannot be done through resorting to literal translation or translating word for word. However, the process of translating Najd dialect necessitates understanding the world out of which the dialect has been produced to real-life. Dialect derives its meaning from its cultural realities and from its historical context. Since it is an oral form of speech is always changeable and derives its meaning from its larger context. That is to say, the translator never understands the language of dialect but the historical and cultural context which help produce them.

This study presents the following recommendations: 
a) The dialectal words should be linguistically analyzed from time to time in order to make sure whether or not these words preserve their original meanings or not. In case of any change to the meaning, socio-linguistics studies should be done in order to investigate the reasons of such changes.

b) The translator who is concerned with translating dialect should culturally belong to the same region of the dialect in order to be fully aware of the ambiguous and ambivalent meanings of the dialect.

c) The cultural concept of translation has to be employed when translating dialects into English.

\section{References}

AbDelMeHSSN, K. (1997) A Study of Najd Dialect, Riyadh: Alnebras Publishing House.

AlgeBALI, A. (1990) Letters from the Tradition, Riyahd: AlmahrajanAlwatni le torath and thaqfa.

AlaWEAI, M. (1994) A Reading of the Tradition, Riyadh: King Fahd Publishing house.

AL-SAUDIS , A. (1950) "A Critical and Comparative Study of Modern Najd Arabic Proverbs", PhD thesis, University of Leeds.

ANIS, I. (1952) Arabic Dialects, Cairo: Anglo Publishing House.

Armstrong, N. (2005) Translation, Linguistics, Culture: A French English Handbook, Clevedon: Multilingual Matters.

BAKeR, M. \& K. MALmkJAer (1998/2001) Encyclopedia of Translation Studies, London: Routledge.

BeHnstedt, P. (2009) "Word and Things", Arabic Dialectology, Netherlands: Brill Publishing House, 60-72.

Cappuccio, D. (2005) Translating Neapolitan Dialect in Theatre: Problems of Cultural Transfer. California: California Scholarship Press.

CATFORD, J. C. (1965) A Linguistic Theory of Translation, Oxford: Oxford University Press.

Chambers, J. K. \& P. TRUdGill (1998) Dialectology London: Cambridge University Press.

DICKINS, J. (1990) Thinking Arabic Translation, London: Routledge.

Even-Zohar, I. (1990) "Polysystems Studies", Poetics Today, 11, 1, 9-26.

Ferguson, C. A. (1959) “Diglossia”, Word, 15, 35-401.

HAMED, A. $(1990)^{2}$ The Arabic Dialects: Establishment and Development, Cairo: Al-Azhar Publishing. 
Dialectologia 19 (2017), 93-107.

ISSN: 2013-2247

HINSKEnS, F., P. AUER et al. (2005) Dialect Change Convergence and Divergence in European Languages, London: Cambridge University Press.

JAKOBSON, R. (1959) “On Linguistic Aspects of Translation”, in Reuben A. Brower (ed.), On Translation. Harvard: Harvard University Press, pp. 232-239.

MezID, B. (2008) "The Golden Middle in Translating from Arabic, e.g. into English", $1^{\text {st }} / n^{\prime} t$ Conference on Translation/Interpretation and the Impact of Globalization, Nov. 18-20, 2008-UAE, United Arab Emirates University.

Munday, J. (2001) Introducing Translation Studies: Theories and Application, London: Routledge.

NIDA, E. (1964) Toward a Science of Translating, Netherlands: E. J. Brill.

REISS, K. (2000) “Type, kind and individuality of text: decision making in translation", in L. Venuti, The translation studies reader, London: Routledge.

ThOMPSON, Ellen \& Sawsan Werfelli (2012) "The Position of the Subject in Spoken Saudi Arabic: A Processing Perspective", Tucson, 19, 20-30.

VENUTI, L. (ed.) (2000) The Translation Studies Reader, London: Routledge.

VERMEER , H. (1989) Skopos and translation Commission, Heidelberg: Universitat.

VeRSTEEGH, K. (1997) The Arabic Language Study, USA: Columbia University Press.

VinAY, P. \& J. DARBELENT (1995) Comparative Stylistics of French and English: A Methodology for Translation, Netherlands: Benjamin Publishing House.

Online sources:

Oxford Dictionary of Proverbs < http/www.oxforddictionaries.com> (Retrieved August, 13, 2014). 